\title{
Prevalence and risk factors for postpartum depression among women seen at Primary Health Care Centres in Damascus
}

\author{
Mayada Roumieh ${ }^{1}$, Hyam Bashour ${ }^{2^{*}}$ (D) Mayada Kharouf ${ }^{2}$ and Salah Chaikha ${ }^{1}$
}

\begin{abstract}
Background: In Syria, there are no previous studies on postpartum depression. The aim of this study is was identify the prevalence of postpartum depression and investigate its risk factors among Syrian women seen at the Primary Health Care Centres in Damascus.

Methods: This descriptive cross-sectional study was carried out between January and December 2017 in Damascus, Syria. Postpartum women seen at a convenience sample of the largest and well-utilized primary health care centres in Damascus were invited to participate in the study. The Arabic version of the validated Edinburgh Postnatal Depression Scale questionnaire was used to measure postpartum depression. A cut-off score of 13 was considered to indicate probable depression.

Results: Out of a total of 1105 women participated in this study, 28.2\% had a score of 13 (probable Depression). The multivariate analysis showed that postpartum depression was significantly associated with a reported a health problem during last pregnancy $(\mathrm{OR}=2.2 ; 95 \%$ confidence interval $[\mathrm{Cl}]$ : 1.4-3.5); displacement $(\mathrm{OR}=1.4 ; 95 \%$ confidence interval [Cl]: 1.04-1.97); perceived exposure to a lot of life stressors (OR $=5.04 ; 95 \%$ confidence interval [CI]: 2.4-10.5); while antenatal care had a protective effect ( $\mathrm{OR}=0.52 ; 95 \%$ confidence interval [Cl]: 0.36-0.75).

Conclusions: The prevalence of postpartum depression among Syrian women in this study was relatively high, as compared to other Arab and Non-Arab countries. Displacement due to the Syrian crisis among other factors was associated with postpartum depression. Obstetricians and other professionals should be sensitized about the importance of screening for the problem for better management.
\end{abstract}

Keywords: Postpartum depression, Women, Prevalence, Risk factors, Syria

\section{Background}

According to the World Health Organization, about 10\% of pregnant women worldwide and $13 \%$ of women who have just given birth experience a mental disorder, primarily depression. Common Perinatal Mental Disorders (CPMDs) are more prevalent in low- and lower-middleincome countries; i.e. $15.6 \%$ of women in low and lowermiddle-income countries experienced a mental disorder during pregnancy and $19.8 \%$ experienced a mental disorder after childbirth $[1,2]$.

\footnotetext{
* Correspondence: hbashour@scs-net.org

${ }^{2}$ Department of Family and Community Medicine, Faculty of Medicine,

Damascus University, Damascus, Syria

Full list of author information is available at the end of the article
}

Postpartum depression (PPD); a non-psychotic depressive disorder classified by the Diagnostic and Statistical Manual of Mental Disorders as an Episode of Major Depressive Disorder that begins within 4 weeks of childbirth [3], is a major disabling mood disorder that affects women during childbearing years. Social factors that are associated with developing PPD include stressful life events, childcare stress, and prenatal anxiety. In addition, a history of the previous episode of PPD, marital conflict, and single parenthood are also predictive of PPD [4]. Lack of social support during pregnancy, is a relatively potent risk factor for postpartum depression, particularly in the form of high levels of depressive symptomatology $[4,5]$. A recent Cochrane review indicated that psychosocial and psychological interventions,

(c) The Author(s). 2019 Open Access This article is distributed under the terms of the Creative Commons Attribution 4.0 International License (http://creativecommons.org/licenses/by/4.0/), which permits unrestricted use, distribution, and reproduction in any medium, provided you give appropriate credit to the original author(s) and the source, provide a link to the Creative Commons license, and indicate if changes were made. The Creative Commons Public Domain Dedication waiver (http://creativecommons.org/publicdomain/zero/1.0/) applies to the data made available in this article, unless otherwise stated. 
delivered by well-trained non-specialist health care providers, including the provision of intensive, professionallybased postpartum home visits, telephone-based peer support, and interpersonal psychotherapy significantly reduce the number of women who develop PPD [6].

There have been many systematic reviews of studies dealing with perinatal mental disorders in women worldwide and in specific regions, including Asia and Africa [7-9]. However, studies on PPD in the Middle East and the Arab World are scarce and have many methodological limitations. For instance, the literature review carried out by Hague at al [10]. of studies in the Middle East and the Arab World revealed that there was a great variation in the prevalence of PPD among the studied women ranging from 10 to $51.8 \%$. Such variation in prevalence was possibly explained by the methodological limitations and differences in the design of the reviewed studies, which made comparison in the prevalence of PPD across different studies and consequently different regions almost impossible. Methodological limitations of the studies were noted as a possible explanation of the variation in prevalence [10]. For example, 51.8\% PPD prevalence in Egypt is very high followed by $43 \%$ in West Bank and $41 \%$ in Iran. Studies such as that in Tunisia [11] and Oman [12] used prospective design while others used cross sectional designs.

Syria, a Middle Eastern country that experienced a major humanitarian crisis in recent years, has no previous studies on PPD. However, the mental health of Syrian people is worrisome according to the World Health Organization [13]. Syrian women have high fertility rates and they have always faced major health challenges including the low uptake of postnatal care [14, 15] though the coverage with antenatal care was very high in the country prior to war [14].

This study was conducted to investigate the prevalence of postpartum depression among Syrian women seen at primary health care centers in Damascus and identify associated risk factors.

\section{Methods \\ Design}

This is a descriptive cross sectional study that was carried out in Damascus city, the capital, between January and December 2017. Women seen at eight largest primary health care centres in Damascus representing the eight health districts in the city. The largest and the most utilized primary health care centre in each district was targeted based on statistical data shared by the health directorate, noting that some primary health care centres were out of coverage due to the current conflict [16].

\section{Participants}

All women who recently gave birth (30-45 days postnatal) seen at the selected primary health care centres were recruited for this study. Sample size was determined based on an estimated prevalence of depressive symptoms amongst women in neighboring countries at anywhere from $15 \%$ onwards. Minimum required sample size was calculated using the prevalence formula then we allowed for design effect. An estimated sample of 1200 women was aimed at.

\section{Data collection}

The Arabic version of the well-known validated Edinburgh Postnatal Depression Scale questionnaire [17-19] was used to measure postpartum depression. The Edinburgh Postnatal Depression Scale (EPDS) was translated and validated in Arabic [20] and is widely used in the Arab world. A cut-off score of 13 was considered to indicate probable depression. A specific questionnaire was also designed for the purpose of this study to collect data on women's characteristics and other potential risk factors. The English version of the questionnaire can be viewed in Additional file 1.

Three trained nurses/midwives at each primary health centre collected the data. The three nurses were recruited from the family planning clinics, the vaccination clinic as well as the internal medicine clinic (one each). Those clinics were used for recruitment purposes as postpartum women are expected to be seen there. The distribution of the women between the eight PHC centres was nearly even except for one centre that underwent reconstruction work.

\section{Data management}

Data from the field were checked for quality and entered using Excel. Data were then analyzed using the Statistical Package or the Social Sciences (SPSS), Version 22 (IBM, Chicago, Illinois, USA). All variables were subjected to univariate and bivariate analysis to determine associations between postpartum depression and women's characteristics. To determine the main factors associated with postpartum depression and to allow for confounders, we conducted a multivariate analysis using logistic regression where we included in the model variables that showed significant associations with postpartum depression in the bivariate analysis at the $P=0.050$ level.

\section{Ethical considerations}

All women gave written informed consent prior to their inclusion in the study. Women with high scores on EPDS or suicidal ideation were referred for a follow up at a specialist mental health clinic through the health centre.

The Ethics Review Committee at the Faculty of Medicine, Damascus University approved the study. The approval of Ministry of Health to access the primary Health Care centres was also obtained. 


\section{Results}

\section{Characteristics of participants}

A total of 1105 women were recruited for this study. Five hundreds and ten women were recruited from the family planning clinics at the PHC centres (46.5\%) while 458 women came from vaccination clinics (41.7\%) and the rest were seen at other clinic.

Table 1 shows the socio demographic characteristics of the women. The mean age was 27.7 years $(\mathrm{SD}=6)$. The percentage with high education was $18.6 \%$ and those who work outside the house was $17.7 \%$. Fortyeight percent did not live in a separate house and $11.8 \%$ shared the house with three families or more, and of importance to note that $46.5 \%$ of the women reported that they were internally displaced (forced or obliged to leave their homes as a result of the current conflict in the country).

Table 2 shows the obstetric history and last pregnancyrelated care of the women in the study. $33.1 \%$ were primigravida, $53.9 \%$ reported a delivery by $\mathrm{C}$-section and $16.3 \%$ reported a health problem during pregnancy.

As shown in Table 3,10.9\% of the women reported a mental health during last pregnancy and $28.9 \%$ perceived that they were exposed to many life stressors, however $61.2 \%$ felt that were supported by family members during postpartum period.

Table 1 The socio-demographic characteristics of the study population

\begin{tabular}{llll}
\hline & & No & $\%$ \\
\hline Mean Age (SD) & & $27.7(6)$ & \\
Mean Age at Marriage (SD) & Illiterate/R Or W & 39 & 3.6 \\
Women's Education & Basic & 515 & 47 \\
& Secondary & 337 & 30.8 \\
& High & 204 & 18.6 \\
Women's work status & No & 910 & 82.3 \\
& Yes & 195 & 17.7 \\
Husband's Education & Basic or illiterate & 554 & 50.9 \\
& Secondary/High & 534 & 49.1 \\
Husband's work & No & 30 & 2.7 \\
Lives in a separate house & Yes & 1060 & 97.2 \\
& Yes & 586 & 53 \\
No. of families sharing the house & No & 519 & 47 \\
& 2 & 580 & 52.7 \\
Internal displacement due to war & Yes & 390 & 35.5 \\
& No & 130 & 11.8 \\
& & 505 & 46.5 \\
& & 580 & 53.5 \\
& & &
\end{tabular}

Table 2 Obstetric history and last pregnancy-related care of the women

\begin{tabular}{lll}
\hline & No. & $\%$ \\
\hline Primigravida & 365 & 33.1 \\
Premature delivery & 15 & 1.4 \\
Delivery at Hospital (mainly public) & 986 & 98.9 \\
Delivered by C-Section & 594 & 53.9 \\
Female care provider attended the delivery & 645 & 58.4 \\
Received 5 or more antenatal visits during last pregnancy & 860 & 79 \\
Reported a health problem/complication during pregnancy & 180 & 16.3 \\
Reported a complicated delivery & 79 & 7.2 \\
Woman's perceived pregnancy as normal & 1021 & 92.5 \\
Woman's perceived delivery as normal & 937 & 85 \\
\hline
\end{tabular}

\section{Prevalence and risk factors}

This study showed that $28.2 \%$ (312 women) had a score of 13 or more on the EPDS, which refers to probable depression, while 229 women (20.7\%) scored $10-12$ on the EPDS, which refers to possible depression. Only seven women had the thought of harming themselves with suicidal thoughts (EPDS, question 10).

The bivariate analysis indicated that postpartum depression was significantly associated with demographic factors (younger age at marriage), socio-economic factors (women and husbands' lower level of education), pregnancy-related factors (poor antenatal care; delivery at public hospital), conflict-related factors (displacement; multiple families at house; perceived exposure to a lot of life stressors/pressure), and health-related factors, including a reported health problem during pregnancy; reported a mental health problem; and having a newborn with health problems).

Logistic regression analysis (Table 4) revealed that postpartum depression was significantly associated with a reported a health problem during last pregnancy $(\mathrm{OR}=$ 2.2; 95\% confidence interval [CI]: 1.4-3.5); displacement $(\mathrm{OR}=1.4 ;$ 95\% confidence interval $[\mathrm{CI}]: 1.04-1.97)$; perceived exposure to a lot of life stressors (OR $=5.04 ; 95 \%$ confidence interval [CI]: 2.4-10.5); while antenatal care had a protective effect $(\mathrm{OR}=0.52 ; 95 \%$ confidence interval [CI]: 0.36-0.75).

Table 3 The reported and perceived health status of the women

\begin{tabular}{lll}
\hline & No. & $\%$ \\
\hline Reported the existence of a chronic problem & 61 & 5.6 \\
Reported a mental health problem (lifetime) & 101 & 9.2 \\
Reported a mental health problem (last pregnancy) & 119 & 10.9 \\
Perceived exposure to a lot of life stressors/pressure & 318 & 28.9 \\
Feeling supported during postpartum period & 674 & 61.2 \\
\hline
\end{tabular}


Table 4 Logistic regression analysis of risk factors for postpartum depression among the women under study

\begin{tabular}{|c|c|c|c|c|}
\hline & & Proportion with Probable depression $(\mathrm{No}, \%)$ & OR & $95 \% \mathrm{Cl}$ \\
\hline \multirow[t]{2}{*}{ Reported a health problem during pregnancy } & Yes & $93,51.7 \%$ & 2.2 & $1.4-3.5$ \\
\hline & No & $218,23.6 \%$ & 1 (Ref) & \\
\hline \multirow[t]{2}{*}{ Received Antenatal care (5 visits or more) } & Yes & $219,25.5 \%$ & 0.52 & $0.36-0.75$ \\
\hline & No & $89,39 \%$ & 1 (Ref) & \\
\hline \multirow[t]{2}{*}{ Being Displaced from her residence } & Yes & $178,35.2 \%$ & 1.4 & $1.04-1.97$ \\
\hline & No & $128,22.1 \%$ & 1 (Ref) & \\
\hline \multirow[t]{3}{*}{ Perceived exposure to a lot of life stressors/pressure } & Yes & $160,50.3 \%$ & 5.04 & $2.4-10.5$ \\
\hline & As usual & $150,20.6 \%$ & 2.03 & $0.99-4.1$ \\
\hline & No at all & $10,9.8 \%$ & 1 (Ref) & \\
\hline
\end{tabular}

\section{Discussion}

This study reported, for the first time in Syria, the prevalence of postpartum depression among a sample of Syrian women who lived in Damascus in 2017. The prevalence of probable depression was $28.2 \%$ using the 13 cut off point. This prevalence is higher than that reported in developed countries and some Arab countries [10]. The one recent study that reported similar prevalence was conducted in Bethlehem, Palestine [21].

It is important to note the main determinants of postpartum depression in our study were a reported health problem during last pregnancy, perceived exposure to a lot of life stressors as well as displacement being a conflict-related risk factors. Interestingly, those who reported utilizing antenatal care reported nearly 50\% reduction in the prevalence of postpartum depression.

Immigrants face unique and multiple layers of challenges that may compromise their mental health and prevent them from receiving adequate and equitable care. For immigrant women, many of the stressors are especially compounded in the vulnerable postpartum period, resulting in PPD $[22,23]$. Maternal depression was an important feature in Syrian refugee women recently resettled in Canada, in a mixed methods research design included 12 Syrian refugee women who migrated to Saskatoon in 2015-16 [24]. Thus, in our study, the issue of internal displacement as an important determinant of postpartum depression, indicate that more research is needed as to define the psychological, social and services variables related it; that could result in depressive symptoms. The number of internally displaced population in the country was over 6 million according to UNHCR [25].

The main limitations of this study include the issue of design which was not prospective and further that the recruitment was only from women who are using the primary health care centres.

\section{Conclusion}

The findings of this study should alert Syrian health professionals that postpartum depression needs to be screened for in the usual antenatal and postnatal care of Syrian women. This study indicated that nearly one of three women have postpartum depression, this means that the burden of mental health in Syria is huge. This burden is not only on women but also on their children and families. Our findings are concerning, recognizing that the promotion of mental health and wellbeing is among health priorities of the global development agenda, as Target 3.4 of the Sustainable Development Agenda requests that countries: "By 2030, reduce by one third premature mortality from non-communicable diseases through prevention and treatment and promote mental health and well-being.".

\section{Supplementary information}

Supplementary information accompanies this paper at https://doi.org/10. 1186/s12884-019-2685-9.

Additional file 1. The research instrument in English.

\section{Abbreviations}

Cl: Confidence interval; CPMD: Common Perinatal Mental Disorders; EPDS: Edinburgh Postnatal Depression Scale; OR: Odds ratio;

PPD: Postpartum depression; WHO: World Health Organization

\section{Acknowledgements}

We would like to acknowledge the support of Dr. Reem Dihaman; the director of the Reproductive Health Division at the Syrian Ministry of Health for her full engagement and facilitation of the work. We also like to thank the directors and the health staff of the eight primary health care centres. We appreciate the time given by the women who participated in the study. We also acknowledge members of the Reproductive Health Working Group (RHWG) who gave useful comments to the authors on earlier oral presentation of this work. We also thank Dr. Rima Mourtada for giving helpful comments on this paper.

\section{Authors' contributions}

All authors contributed to the design of the study. MR, MK and HB supervised the field work. SC followed on the women who scored high on EPDS or with suicidal ideation and who were referred to a mental health specialist. MK supervised the data entry and assured the quality of data. $H B$ analyzed the data. MR and HB contributed to the writing the manuscript. All authors read and approved the final manuscript.

\section{Funding}

This study was funded by Damascus University. There are no role of the funding body in preparing this manuscript. 


\section{Availability of data and materials}

All materials and dataset for this study are available from the corresponding author on reasonable request and approval of all co-authors.

\section{Ethics approval and consent to participate}

The Ethics Review Committee at the Faculty of Medicine, Damascus University approved the study. The approval of Ministry of Health to access the primary Health Care centres was also obtained. All women gave written informed consent prior to their inclusion in the study.

\section{Consent for publication}

Not applicable.

\section{Competing interests}

The authors declare that they have no competing interests.

\section{Author details}

'Department of Obstetrics and Gynecology, Faculty of Medicine, Damascus University, Damascus, Syria. ${ }^{2}$ Department of Family and Community Medicine, Faculty of Medicine, Damascus University, Damascus, Syria.

Received: 5 June 2018 Accepted: 17 December 2019

Published online: 23 December 2019

\section{References}

1. World Health Organization. maternal mental health. [online] Available at: http://www.who.int/mental_health/maternal-child/maternal_mental_health/ en/. Accessed 15 Mar 2018

2. Fisher J, MCd M, Patel V, Rahman A, Tran T, Holton S, Holmes W. Prevalence and determinants of common perinatal mental disorders in women in low and lower-middle-income countries: a systematic review. Bull World Health Organ. 2012:90(2):139-49.

3. American Psychiatric Association. Diagnostic and statistical manual of mental disorders: DSM-5. 5th ed. Washington D.C: American Psychiatric Publishing; 2013

4. Anokye R, Acheampong E, Budu-Ainooson A, Obeng El, Akwasi AG Prevalence of postpartum depression and interventions utilized for its management. Ann General Psychiatry. 2018;17:18. https://doi.org/10.1186/ s12991-018-0188-0.

5. Robertson, E., Celasun, N., and Stewart, D.E. (2003). Risk factors for postpartum depression. In Stewart, D.E., Robertson, E., Dennis, C.-L., Grace, S. L., Wallington, T. Postpartum depression: literature review of risk factors and interventions. University Health Network Women's Health Program. Toronto.

6. Dennis CL, Dowswell T. Psychosocial and psychological interventions for preventing postpartum depression. Cochrane Database of Systematic Reviews 2013, Issue 2. Art. No.: CD001134. doi: https://doi.org/10.1002/ 14651858.CD001134.pub3.

7. Mirza I, Jenkins R. Risk factors, prevalence, and treatment of anxiety and depressive disorders in Pakistan: systematic review. BMJ. 2004:328:794-7. https://doi.org/10.1136/bmj.328.7443.794.

8. Halbreich U, Karkun S. Cross-cultural and social diversity of prevalence of postpartum depression and depressive symptoms. J Affect Disord. 2006;91: 97-111. https://doi.org/10.1016/j.jad.2005.12.051.

9. Upadhyay RP, Chowdhury R, Salehi A, Sarkar K, Singh SK, Sinha B, Pawar A, Rajalakshmi AK, Kumar A. Postpartum depression in India: a Systematic review and meta-analysis. Bull World Health Organ. 2017:95:706-717C. https://doi.org/10.2471/BLT.17.192237.

10. Haque A, Namavar A, Breene K. Prevalence and risk factors of postpartum depression in middle eastern/Arab women. J Muslim Ment Health. 2015;9. https://doi.org/10.3998/jmmh.10381607.0009.104.

11. Masmoudi J, Charfeddine F, Trabelsi S, Feki I, Ben Ayad B, Guermazi M, Baâti I, Jaoua A. Postpartum depression: prevalence and risk factors. A prospective study concerning 302 Tunisian parturients. Tunis Med. 2014 Oct;92(10):615-21.

12. Al Hinai Fl, Al Hinai SS. Prospective study on prevalence and risk factors of postpartum depression in Al-dakhliya governorate in Oman. Oman Med J. 2014 May;29(3):198-202. https://doi.org/10.5001/omj.2014.49.

13. World Health Organization. Syrian Arab Republic Annual Report 2017. Cairo: WHO; 2018

14. Syrian Central Bureau of Statistics, League of Arab States. Family Health Survey in Syrian Arab Republic, vol. 2009; 2011
15. Bashour HN, Kharouf MH, Abdulsalam AA, El Asmar K, Tabbaa MA, Cheikha SA. Effect of a Community-based Intervention on postnatal outcomes: A Randomized Controlled Study in Syria. Public Health Nurs. 2008;25(2):115-25.

16. World Health Organization. HeRAMS Annual Public Health Centres Report. Cairo: WHO; 2017

17. Cox JL, Holden JM, Sagovsky R. Detection of postnatal depression. Development of the 10-item Edinburgh postnatal depression scale. Br 」 Psychiatry. 1987;150:782-6.

18. Gibson J, McKenzie-McHarg K, Shakespeare J, Price J, Gray R. A systematic review of studies validating the Edinburgh postnatal depression scale in antepartum and postpartum women. Acta Psychiatr Scand. 2009;1 19:350-64.

19. Boyd RC, Le HN, Somberg R. Review of screening instruments for postpartum depression. Arch Womens Ment Health. 2005:8:141-53.

20. Ghubash R, Abou-Saleh MT, Daradkeh TK. The validity of the Arabic Edinburgh postnatal depression scale. Soc Psychiatry Psychiatr Epidemiol. 1997 Nov;32(8):474-6.

21. Qandil S, Jabr S, Wagler S, Collin SM. Postpartum depression in the occupied Palestinian territory: a longitudinal study in Bethlehem. BMC Pregnancy Childbirth. 2016;16(1):375.

22. Fung K, Dennis CL. Postpartum depression among immigrant women. Curr Opin Psychiatry. 2010;23(4):342-8. https://doi.org/10.1097/YCO. Ob013e32833ad721.

23. Alhasanat D, Fry-McComish J. Postpartum Depression Among Immigrant and Arabic Women: Literature Review. J Immigr Minor Health. 2015;17(6): 1882-94. https://doi.org/10.1007/s10903-015-0165-5.

24. Ahmed A, Bowen A, Feng X. Maternal depression in Syrian refugee women recently moved to Canada: a preliminary study. BMC Pregnancy Childbirth. 2017;17:240. https://doi.org/10.1186/s12884-017-1433-2

25. UNHCR. Internally Displaced People in Syria. Available at: http://www.unhcr. org/sy/internally-displaced-people.

\section{Publisher's Note}

Springer Nature remains neutral with regard to jurisdictional claims in published maps and institutional affiliations.

Ready to submit your research? Choose BMC and benefit from:

- fast, convenient online submission

- thorough peer review by experienced researchers in your field

- rapid publication on acceptance

- support for research data, including large and complex data types

- gold Open Access which fosters wider collaboration and increased citations

- maximum visibility for your research: over $100 \mathrm{M}$ website views per year

At $B M C$, research is always in progress.

Learn more biomedcentral.com/submission 